\title{
Prolongation of a pregnancy with second trimester severe oligohydramnios to term: a case report
}

\author{
Alka C. Bapat*, Nitin P. Paidhungat \\ Department of Obstetrics and Gynecology, Bombay Hospital Institute of Medical Sciences, Mumbai, Maharashtra,
} India

Received: 14 May 2019

Revised: 30 May 2019

Accepted: 11 June 2019

\section{*Correspondence:}

Dr. Alka C. Bapat,

E-mail: bapat.alka@gmail.com

Copyright: $\odot$ the author(s), publisher and licensee Medip Academy. This is an open-access article distributed under the terms of the Creative Commons Attribution Non-Commercial License, which permits unrestricted non-commercial use, distribution, and reproduction in any medium, provided the original work is properly cited.

\begin{abstract}
The occurrence of oligohydramnios complicating a pregnancy is seen in 0.8 to $5.5 \%$ of pregnancies. Severe Oligohydramnios, though not clearly defined, but clinically with an AFI of less than $5 \mathrm{~cm}$ appears to be an important predictor for an abnormal fetal outcome. In general, the prognosis of mid trimester oligohydramnios is still poor. Hence we report a case with a very favourable neonatal outcome following severe oligohydramnios documented in early pregnancy. The aim of this case report is to add our experience to the currently limited literature regarding the best treatment of this unique obstetrical problem.
\end{abstract}

Keywords: Ayurvedic-preparation, Oligohydramnios, AFI, Utero-placental insufficiency

\section{INTRODUCTION}

Amniotic fluid helps in the growth and nourishment of the fetus. It protects the fetus by acting as a cushion and allowing for easier fetal movement. It promotes musculoskeletal development. Amniotic fluid being rich in amino acids, when swallowed by the fetus, helps in the formation and maturation of the gastrointestinal tract. Oligohydramnios is a condition in which the volume of amniotic fluid is reduced. Decreased Amniotic fluid can cause various fetal complications like contractures of the limbs, clubbing of feet and hands, and sometimes a lifethreatening condition called hypoplastic lungs.

It may also result in intrauterine demise of the fetus. Our reported case describes the role of conservative medical management of second trimester severe oligohydramnios and the achieved favourable neonatal outcome provides a ray of hope in this condition, otherwise considered to have a dismal prognosis for the fetus.

\section{CASE REPORT}

A 27 year old, G2 P0 A1 L0, known case of Polycystic Ovarian Syndrome and Hypothyroidism, taking $75 \mathrm{mcg}$ of Thyroxin, with present pregnancy resulting after Ovulation Induction, presented in the Emergency department at 14 weeks with threatened abortion. The patient was given Injection HCG (5000 U) IM twice a week for 2 weeks and oral micronized Progesterone (200 $\mathrm{mg}$ ) twice a day and was discharged on oral medications. Patient presented again after 9 weeks with complaints of leaking per vaginum since 3 weeks. The Ultrasonography report was indicative of severe oligohydramnios (AFI 3 $\mathrm{cm})$. Oligohydramnios complicating a pregnancy is seen in 0.8 to $5.5 \%$ of pregnancies. ${ }^{1}$ Severe Oligohydramnios in early gestation is associated with poor pregnancy outcomes, ${ }^{2}$ which were explained to the patient. On admission, patient was given complete bed rest with bedside toilet facilities, head low position and was started on oral erythromycin $(250 \mathrm{mg})$ four times a day. Two doses of Injection Betamethasone (12 mg) were given 
intramuscularly. Oral amino acid supplements in form of L- arginine+Proanthocyanidins as powder, as well as tablet with multiple amino acids like Alanine, Arginine, Aspartic acid, Cystine, Glutamic acid, Glycine, Histidine, Isoleucine, Leucine, Lysine, Methionine, Phenylalanine, Proline, Serine, Threonine and Tryptophan was given along with Iron and Calcium supplements. Progesterone supplementation was continued. Oral antibiotic was switched to Amoxicillin+Clavulinic acid $(625 \mathrm{mg})$ twice a day for 5 days after urine culture showed a weak growth of E. coli.

Intravenous fluids in the form of alternate DNS and Multivitamins and minerals were given for 1 week, after which an ultrasound was repeated. Repeat USG showed a mild increase in AFI $(5-6 \mathrm{~cm})$ with features suggestive of symmetrical IUGR. Intravenous Cefoperazone+Sulbactam (1.5 g) was given twice a day for 5 days in view of High Vaginal swab showing a growth of Klebsiella pneumoniae. Oral Aspirin $(75 \mathrm{mg}$ ) was started to improve the pregnancy outcome. Intravenous fluids up to $2 \mathrm{~L}$ were given. Oral supplement, commercially available ayurvedic-preparation consisting of extracts of Gokhru, Amla and Ashwagandha plants in tablet form with hydrolysable tannins and vitamin $\mathrm{C}$ was also added. Intravenous fluids were continued throughout the stay of three weeks. Repeat USG after 10 days showed AFI of $6 \mathrm{~cm}$, with gestational age lag of 1.2 weeks. Treatment with Intravenous fluids was continued, Inj.

LMWH (0.4 mg) given by subcutaneous route was added. A repeat USG for interval growth was done after 10 days which showed an increase in the liquor, with AFI $10 \mathrm{~cm}$. T. Metformin $(250 \mathrm{mg}$ ) was started twice a day in view of mildly elevated blood sugars, post 2 hour of $75 \mathrm{~g}$ oral glucose load. Patient was discharged on oral medications after 3 weeks, at a gestational age of 32 weeks. She was followed up once in every 2 weeks and USG Colour Doppler was done at 36 weeks. Patient came in spontaneous active labour at 38 weeks gestational age with leaking PV and decreased perception of fetal movements. She delivered a term male baby vaginally, with forceps assistance. Neonate cried immediately at birth, had a birth weight of $2690 \mathrm{~g}$ and was discharged on day 3 of life.

\section{DISCUSSION}

The prognosis of mid trimester oligohydramnios is reported to be poor. ${ }^{3,4}$ Amniotic fluid serves several roles during pregnancy. It creates physical space for fetal movement and permits fetal swallowing which is essential for gastrointestinal tract development. It facilitates fetal breathing which is necessary for lung development. It has bacteriostatic properties. $^{5}$ Oligohydramnios is defined as amniotic fluid $<5 \mathrm{~cm} .{ }^{6}$

Oligohydramnios in pregnancy is many a time associated with neonatal complications. ${ }^{7}$ Adverse neonatal outcomes usually warrant drastic steps on the part of the Obstetrician. Some studies have shown that amniotic fluid index (AFI) is a predictor of adverse outcome while other authors have not confirmed the association. ${ }^{8-10}$

Oligohydramnios is associated with risk of maternal and foetal morbidities. The risk is secondary to umbilical cord compression and potential utero-placental insufficiency. Therefore, termination of pregnancy is advocated sometimes even in otherwise uncomplicated pregnancies with Oligohydramnios. However, some of the recent studies have shown no adverse effect of isolated oligohydramnios on perinatal outcome and recommend continuation of pregnancy. It may however increase the caesarean section rate. ${ }^{11}$

In the case described by us, the patient was advised termination of pregnancy at a peripheral hospital, as the leaking per vaginum occurred at a very early gestational age of 20 weeks causing Oligohydramnios. However, at our hospital, conservative approach was utilized with resultant moderate increase in the liquor and a favorable neonatal outcome.

Thus, in present case, we report that isolated Oligohydramnios during second trimester does not always increase the risk of adverse perinatal outcome significantly, and hence should not be an indication for termination of pregnancy.

Based on the treatment we used, we recommend the use of intravenous fluids and amino acid supplements for prolonging pregnancy, in case of a small leak. Thus, not every pregnancy with early trimester leaking needs to be terminated. Although risk of infection and chances of preterm labour increase in such cases, it needs to be assessed on a case by case basis to provide the most appropriate management.

Authors encourage that more number of similar cases and series be reported in literature so that a protocol can be set for the appropriate management of the cases. Also, long term studies regarding the developmental aspects of the child need to be documented.

\section{ACKNOWLEDGMENTS}

Authors would like to thank Dr. S. Khadilkar, Head, Department of Obstetrics and Gynecology, Bombay Hospital Institute of Medical Education and Research for support and encouragement.

Funding: No funding sources

Conflict of interest: None declared

Ethical approval: Not required

\section{REFERENCES}

1. Karahanoglu E, Akpinar F, Demirdag E, Yerebasmaz N, Ensari T, Akyol A, et al. Obstetric 
outcomes of isolated oligohydramnios during earlyterm, full-term and late-term periods and determination of optimal timing of delivery. J Obstet Gynaecol Res. 2016;42(9):1119-24.

2. Khatun T, Ansari AA, Hamid I, Gupta RS, Ahmad MP. Oligohydramnios and fetal outcome: A Review. Med Phoenix. 2016;1(1):23-30.

3. Brzezinski-Sinai NA, Stavsky M, Rafaeli-Yehudai T, Yitshak-Sade M, Brzezinski-Sinai I, Imterat M, et al. Induction of labor in cases of late preterm isolated oligohydramnios: is it justified?. J Matern Fetal Neonatal Med. 2018;32(14):2271-79.

4. Tahmina S, Prakash S, Daniel M. Maternal and perinatal outcomes of induction of labor in oligohydramnios at term-a retrospective cohort study. J Matern Fetal Neonatal Med. 2018;16:1-5.

5. Cunningham FG, Leveno KJ, Bloom SL, Spong CY, Dashe JS, Hoffman BL, et al. Amniotic fluid. Williams Obstetrics. 24 ${ }^{\text {th }}$ Ed. New York: McGrawHill Education;2014:231.

6. Phelan JP, Smith CV, Broussard P, Small M. Amniotic fluid volume assessment with the fourquadrant technique at 36-42 weeks' gestation. J Reprod Med. 1987;32(7):540-2.

7. Ghimire S, Ghimire A, Chapagain S, Paudel S. Pregnancy outcome in cases of oligohydramnios after 28 weeks of gestation. Int $\mathbf{J}$ Adv Med Health Res. 2016;3(2):68-72.

8. Casey BM, McIntire DD, Bloom SL, Lucas MJ, Santos R, Twickler DM, et al. Pregnancy outcomes after antepartum diagnosis of oligohydramnios at or beyond 34 weeks' gestation. Am J Obstet Gynecol. 2000;182(4):909-12.

9. Locatelli A, Zagarella A, Toso L, Assi F, Ghidini A, Biffi A. Serial assessment of amniotic fluid index in uncomplicated term pregnancies: Prognostic value of amniotic fluid reduction. J Maternal Fetal Neonatal Med. 2004;15:233(4)-6.

10. Chauhan SP, Hendrix NW, Morrison JC, Magann EF, Devoe LD. Intrapartum oligohydramnios does not predict adverse peripartum outcome among high-risk parturients. Am J Obstet Gynecol. 1997;176(6):1130-6.

11. Taneja A, Arora K, Chopra I, Naik SS. Pregnancy Outcomes in Isolated Oligohydramnios during Second Trimester. A Case Series. J Clin Diagn Res. 2017;11(8):QR01-2.

Cite this article as: Bapat AC, Paidhungat NP.

Prolongation of a pregnancy with second trimester severe oligohydramnios to term: a case report. Int $\mathbf{J}$ Reprod Contracept Obstet Gynecol 2019;8:2940-2. 